\title{
FEMINISMO É HUMANISMO - A QUESTÃO DAS MULHERES NA FILOSOFIA
}

\section{FEMINISM IS HUMANISM - THE ISSUE OF WOMEN IN PHILOSOPHY}

\author{
MARTA NUNES DA COSTA ${ }^{1}$ \\ (Universidade Federal Mato Grosso do Sul, Brasil)
}

\begin{abstract}
RESUMO
O objetivo deste artigo é oferecer uma reflexão crítica acerca do tema e questão "mulheres na Filosofia". Começo por dizer aquilo que não farei: não farei uma reconstrução da invisibilidade das mulheres ao longo da história da filosofia; não farei uma catalogação das estratégias usadas pelos homens para silenciar a existência e vozes das mulheres; não tentarei retratar as mulheres através de um olhar masculino, como se houvesse uma natureza especificamente feminina. O que pretendo é diferente: quero proporcionar rasgos de luz que permitam identificar as dinâmicas de visibilidade/invisibilidade das mulheres na atividade filosófica, contribuindo para a transformação do nosso olhar sobre esta questão. Para isso posiciono-me criticamente, isto é, a partir do uso de dados empíricos acerca da presença das mulheres nos departamentos de Filosofia e tendo Sally Haslanger como principal interlocutora, trago à superfície alguns mecanismos que parecem reforçar a naturalização da invisibilidade das mulheres e construo de seguida algumas alternativas para repensar o feminismo hoje.

Palavras-chave: Mulheres na Filosofia. Feminismo. Igualdade. Teoria crítica.
\end{abstract}

\begin{abstract}
In this paper I offer a critical reflection upon the theme and question of "women in philosophy". This paper is not about reconstructing the invisibility of women throughout history; nor is it a description of a set of strategies used by men to silence women; it is not a portray of women via a man's glance. Instead, this paper provides glimpses of light that hopefully will allow us to identify the dynamics of visibility/invisibility of women in philosophical activity, contributing to change the way we look and approach this question. In order to do so I start from a critical stance : having Sally Haslanger as main interlocutor and resting upon recent data about women's presence in philosophy departments I bring to the surface some mechanisms that appear to strengthen the naturalization of women's invisibility and I then offer some alternatives to reconceptualize feminism today.
\end{abstract}

Keywords: Women in philosophy. Feminism. Equality. Critical theory.

A presença das mulheres na Filosofia é raramente tópico de discussão acadêmica e produção científica. Como abordar este tema, e de que forma ele se torna problemático? Como e porquê o tema das mulheres na Filosofia torna-se uma questão a ser discutida?

Penso que há pelo menos três perspetivas possíveis de análise: a primeira, reflete sobre o problema da atividade da filosofia feita por mulheres. Sem entrar aqui no que constitui efetivamente esta atividade, mas partindo do princípio de que a filosofia é uma busca pela sabedoria e um mergulho profundo na reflexão acerca do sentido das coisas, a começar pelo 
sentido de nós mesmos, penso que todos concordariam em que essa experiência - de reflexão e busca de sentido - é uma experiência fundamental da existência humana, partilhada por homens e mulheres. Mas então, por que sobretudo os homens conferem visibilidade a essa atividade? Aqui, poderíamos olhar para a própria história da filosofia e tentar identificar as formas pelas quais os vários filósofos - homens - justificam ou legitimam a 'exclusão' das mulheres desse domínio específico e privilegiado de pensar. Poderíamos seguir Rousseau, no Segundo Discurso, quando ele diz simplesmente que as mulheres e os homens eram 'iguais' até que, por convenção, no momento da revolução, se determinou que as mulheres ficariam em casa e os homens seriam os provedores. ${ }^{2}$ Assim, por convenção, ou por construção social, as mulheres teriam sido progressivamente excluídas de certas atividades, o que de alguma forma conduz ao estado de coisas atual e o explica, porém não o justifica. Mas quando dizemos que x (neste caso, a diferença de gênero) é uma construção social, o que queremos de fato dizer com isso? Será que estamos a sugerir que x é uma ilusão ou ficção? E a questão de 'raça', é também construção social? Como diz Haslanger, "qual é a ilusão (se é que há) e qual a realidade nas construções sociais?" (HASLANGER, 2012, p.5) Se olharmos para os textos, sabemos que muitas vezes estes são usados como veículos de legitimação de instituições racistas e/ou sexistas, e que essa legitimação se assenta numa visão de 'natureza humana' específica, onde as mulheres e os não-brancos são inferiores. (idem) Mais uma vez, Rousseau tocou num ponto crucial ao mostrar que se a natureza nos faz iguais, não há situação de dominação que seja legítima, já que a lógica de dominação só se afirma à custa da desigualdade, logo, da renúncia e alienação de algo que é inalienável - a liberdade. Porém, como também percebemos por uma leitura atenta de Rousseau, o problema é que as desigualdades são 'naturalizadas', são incorporadas como uma segunda natureza, que é preciso desconstruir para depois construir de novo. E isso obriga-nos a confrontar a relação entre construções sociais e fatos naturais. Do ponto de vista do gênero, isso significa compreender que tipo de papel desempenha este conceito (e suas práticas correlativas) e que tipo de fundamento (que não a 'natureza humana') lhe podemos dar.

Como leitores de textos filosóficos sabemos que outra tendência de (os) homens justificarem e legitimarem a sua visibilidade liga-se à dicotomia razão/paixão, segundo a qual os homens teriam o monopólio ou o privilégio da razão e as mulheres seriam mais determinadas pela paixão ou pela emoção. Assim, poderíamos pensar que a expressão visível do pensamento filosófico se consolida na modernidade a partir de uma depuração do 'ser humano', privilegiando a razão sobre outras esferas - o que será, por sua vez, tema de inquérito por parte de autores como Horkheimer, Adorno, Marcuse, entre muitos outros, mas 
que poderia ser levada ao extremo no que diz respeito ao preço que tivemos de pagar pela 'racionalização' em detrimento da 'paixão'. Enfim, apenas para dizer que esta é uma abordagem possível - a da participação das mulheres na atividade filosófica, e o desdobramento desta participação na lógica de visibilidade/invisibilidade; inclusão/exclusão; razão/paixão.

Uma segunda linha de pesquisa seria a da representação das mulheres na filosofia. A representação supõe o trazer à presença o que está ausente, logo, tratar-se-ia aqui de perceber de que forma as mulheres como ausência, ou como aquilo ou aquelas que estão ausentes são representadas, e esta representação pode ser feita por homens ou por mulheres. Se é feita por homens, como justificar essa representação, ou de que forma essa representação é legitima, se o homem é diferente da mulher? Se é feita por mulheres, o problema é idêntico, embora por outro ângulo: de que forma uma, ou algumas mulheres representam as mulheres que permanecem ausentes? Aqui teríamos o problema ${ }^{1}$ da legitimidade e da universalidade. Mas na realidade estas questões abrem-se para uma outra, mais profunda e anterior a elas: é possível oferecer uma teoria acerca da 'mulher'? É possível postular um sentido, atribuir um significado ao ser mulher? Como determinar esse sentido? E de que forma isso não condiciona os sentidos possíveis desse mesmo conceito e experiência, de ser mulher? Que tipo de abordagem devemos adotar para trabalhar e refletir acerca de categorias sociais, de termos que são complexos e que se abrem a uma contestação perpétua de sentido? Este conjunto de questões remeter-nos-ia a uma longa digressão acerca da forma como as categorias sociais são incorporadas, no sentido literal de ser trazidas para o corpo, assimiladas no corpo, traduzidas pelo corpo; e acerca dos esquemas de subordinação e dominação institucionalizados e naturalizados.

Uma terceira linha de pesquisa seria mais empírica, mais sociológica e política. Partiria de uma análise de fatos, por exemplo, de quantas mulheres existem hoje em cursos de filosofia de graduação e pós-graduação, no Brasil e no Mundo; de quantas mulheres lideram grupos de pesquisa em filosofia; de quantas mulheres se intitulam 'filósofas'. E, aqui, seríamos em última análise levados ao problema de como ler os fatos. Porém, a partir do confronto com os 'dados' somos obrigados a pensar acerca das dinâmicas mencionadas acima; os números são o que são e isto significa que eles revelam e escondem coisas importantes, ao mesmo tempo: os dados podem esconder, por exemplo, o tipo (qualitativo) de relação entre mulheres e homens nas instituições envolvidas; porém, eles se abrem para a 
consideração acerca dessas relações. Vejamos então.

Consideremos alguns dados de vários países: no Reino Unido, até julho de 2015, apenas $24 \%$ dos professores de departamentos de Filosofia eram mulheres. ${ }^{3}$ Nos Estados Unidos, de acordo com a Estatística da Educação de 2003 (e são os dados mais recentes) a percentagem de mulheres em posições de ensino universitário representava apenas 16,6\%, num total de 13 mil filósofos - só neste ano, 27,1\% dos doutorados foram concedidos a mulheres. ${ }^{4}$ Relativamente ao Brasil não encontrei dados prontos, mas fiz uma análise de algumas universidades federais:

UFSC - 23 homens, 6 mulheres, i.e., 79\% homens, 21\% mulheres.

UFMG - 25 homens, 8 mulheres; $75 \%$ vs. $25 \%$

UFG - 15 homens, 7 mulheres, $65 \%$ vs. $35 \%$

UFMS -8 homens, 3 mulheres, $72 \%$, vs. $28 \%$

UFPR - 17 homens, 3 mulheres, $85 \%$, vs. $15 \%$

UFPB - 18 homens, 4 mulheres $82 \%$, vs. $18 \%$

UFPE - 14 homens, 0 mulheres, $100 \%$, vs. $0 \%$

UFRJ - 18 homens, 5 mulheres $78 \%$, vs. $22 \%$

USP - 44 homens, 9 mulheres $83 \%$, vs. $17 \%$

UFSCAR -8 homens, 8 mulheres $50 \%$, vs. $50 \%$

UFMT - 11 homens, 2 mulheres $84 \%$, vs. $16 \%$

UFAL - 14 homens, 6 mulheres $70 \%$, vs. $30 \%$

UFRGS - 14 homens, 7 mulheres, $66 \%$, vs. $34 \%$

UFJF - 12 homens, 0 mulheres $100 \%$, vs. $0 \%$

UFCA - 10 homens, 4 mulheres. $71 \%$, vs. $29 \%$

UFPI -não disponível

UFC - não disponível

UFRN - não disponível

UNIFESP - 26 homens, 12 mulheres, $68 \%$, vs. $32 \%$

UFPA - 12 homens, 5 mulheres $70 \%$, vs. $30 \%$

UFBA - 13 homens, 6 mulheres. $68 \%$, vs $32 \%$

UFLA - 6 homens, 2 mulheres $75 \%$, vs. $25 \%$

UFPel - 10 homens, 2 mulheres. $83 \%$, vs. $17 \%$

UFU - não disponível ${ }^{5}$ 
Em traços largos, se tomarmos esta amostra, vemos que o universo total (de 24 universidades federais, 415 professores) corresponde a uma percentagem de 76,6\% de homens (sub-total de 318) e $23,4 \%$ de mulheres (sub-total de 97). Isto mostra que a realidade brasileira se aproxima da realidade dos outros países no que diz respeito ao desequilíbrio entre homens e mulheres. Mas o que fazer com estes dados? Como explicar este desequilíbrio? Será que isso revela que as mulheres são menos competentes ou aptas para a Filosofia?

Para tentar responder a esta questão temos de responder antes a outra: O que define a Filosofia hoje? Certamente, a filosofia 'profissionalizante' ou 'profissional' exigiu, sobretudo a partir do século XX, o exacerbamento do peso atribuído aos argumentos, mais do que ao filósofo que os dá ou apresenta. Se pensarmos no que isto significa, vemos que a filosofia, tal como prática, tem o potencial de se afirmar (se é que não se afirma de fato) como domínio neutro no que diz respeito à questão do gênero. Afinal, a lógica é neutra; a filosofia do ego, por exemplo, não é masculina nem feminina: o ego ou cogito desde Descartes fornece o campo de possibilidade para que qualquer um - homem ou mulher - o descubra e o preencha consigo. Mas esta pretensão de neutralidade conduz a uma cegueira perigosa sobretudo porque a partir dela se constrói o mito da 'objetividade' do conhecimento e do saber, e essa objetividade só se conquista à custa do sacrifício do sujeito encarnado, homem ou mulher, que é, que pensa, que vive, que existe. Ou seja, a filosofia tem-se afirmado como uma disciplina que se assenta na postulação da igualdade conferida pela 'razão', assim como no mito da neutralidade (como se o sujeito 'racional' não fosse homem nem mulher, ou por outras palavras, como se o fato de ser homem ou mulher não influenciasse em nada o seu pensamento e sua validade). Para 'desconstruir' o estatuto de legitimidade (e superioridade) que a filosofia reclama para si, devemos olhar para fora da filosofia, para outras disciplinas, sobretudo, e neste caso específico, para a psicologia. Aqui, não podemos ignorar as contribuições do trabalho de Sally Haslanger e Jennifer Saul acerca do modo como os fenómenos psicológicos (como preconceitos implícitos e estereótipos) trabalham e atuam sobre o sujeito.

De acordo com uma pesquisa recente realizada pela British Philosophical Association, intitulada "Women in Philosophy in the UK", há pelo menos três explicações para este desequilíbrio entre gêneros - a do preconceito implícito, a dos estereótipos e a do assédio, todas elas 'justificadas' do ponto de vista dos estudos psicológicos. O objetivo desta pesquisa foi identificar a sub-representação das mulheres nos departamentos de filosofia, buscando uma explicação para esta. ${ }^{6}$ Para o nosso propósito quero olhar para as duas primeiras 
'barreiras' que podem explicar a pouca presença de mulheres nos departamentos de filosofia.

A hipótese do preconceito implícito foi corroborada a partir de uma análise de casos em que currículos eram avaliados por uma equipe. $\mathrm{O}$ fato do nome do $\mathrm{CV}$ ser masculino gerou melhores avaliações para o ensino, pesquisa e experiência, o que por sua vez conduziu a uma probabilidade maior de um homem ser contratado, em detrimento de uma mulher. Como diz Haslanger:

\footnotetext{
Tal como filósofas feministas defendem há décadas, as dicotomias familiares com as quais a filosofia anglo-saxônica se define encaixam-se perfeitamente em dicotomias de gênero - racional/emocional, objetivo/subjetivo, mente/corpo; ideais da filosofia - penetrantes, seminais, e rigorosas; e aquilo que nós fazemos - atacar, apontar e demolir um oponente, todos dos quais enquadram a filosofia como masculina e em oposição ao feminino. (HASLANGER, 2008, p.213).
}

Além disso, a filosofia analítica repousa sobretudo na lógica, e há uma longa lista de pesquisa que mostra que a matemática é estereotipada como masculina. ${ }^{7}$

Por sua vez, no que diz respeito ao peso do estereótipo, de acordo com a mesma pesquisa, "mais do que afetar a forma como os membros de um grupo estigmatizado são percebidos ou avaliados, a ameaça do estereótipo afeta a forma pela qual os membros desse grupo agem de fato. As vítimas da ameaça do estereótipo agem com deficit (underperform) porque estão inconscientemente preocupadas por medos de confirmar os estereótipos acerca do seu grupo - tão preocupadas que inclusive mostram aumento de batimento cardíaco e pressão sanguínea" (2011).

O que isto significa na prática é que a atuação do estereótipo sobre o agente conduz a que este confirme, na maioria dos casos, a hipotética validade desse mesmo estereótipo. Quando essa ameaça é retirada verifica-se que a performance melhora significativamente, muitas vezes ao ponto de atingir a igualdade.

Estas duas explicações são apenas isso - duas explicações que nos satisfazem, parcialmente, na tentativa de compreender por que as coisas são como são. Ora, o impulso que guia essa análise e busca de explicação reside na intuição de que o que é não coincide com o que deve ser; logo, que uma consciência acerca das razões que conduziram ao atual estado de coisas nos pode libertar dos 'mitos' e criar as condições para a criação do novo - do restabelecimento de um equilíbrio perdido, que talvez nunca tenha existido, mas que nem por isso deixa de ser motivo válido para aqueles que se comprometem com algum tipo de justiça (social).

Se pensarmos na herança da teoria crítica, por exemplo, vemos que uma das suas 
maiores contribuições para a filosofia (mas também para uma gama vasta de disciplinas) foi situar a teoria num tempo e espaço, questionando as interpretações naturalizadas da própria atividade filosófica. Nancy Fraser oferece-nos uma leitura ajustada da teoria crítica:

\begin{abstract}
Para mim, ninguém ainda melhorou a definição dada por Marx, em 1843, da Teoria Crítica como "a auto-clarificação de lutas e desejos de uma época". O que é tão apelativo nesta definição é o seu carácter manifestamente político. Ela não reivindica um estatuto especial epistemológico, pelo contrário, ela assume que, no que diz respeito à justificação, não há uma diferença filosófica significativa ou interessante entre uma teoria crítica da sociedade e uma teoria não-crítica. Mas há, de acordo com esta definição, uma diferença política importante. Uma teoria crítica social enquadra o seu programa de pesquisa e aparato conceptual tendo em conta os objetivos e atividades desses movimentos sociais de oposição com os quais tem uma identificação partidária - embora não acrítica. As questões que coloca e os modelos que desenha são informados e delineados por essa identificação e por esse interesse. Assim, por exemplo, se as lutas que contestam a subordinação das mulheres aparecem como as mais significativas de uma determinada época, então uma teoria crítica social da sociedade para essa época tem como objetivo, entre outros, iluminar o carácter e as bases dessa subordinação. Irá empregar categorias e modelos explicativos que sejam capazes de revelar (e não ocultar) as relações de dominação masculina e subordinação feminina. E irá desmistificar as abordagens ideológicas rivais que ofuscam ou racionalizam essas relações. Nesta situação, um dos critérios para determinar uma teoria crítica, que tenha sido sujeita aos testes usuais de adequação empírica, será: quão bem é que esta teoria teoriza acerca da situação e das intenções do movimento feminista? Até que ponto é que ela é capaz de autoclarificar as lutas e desejos de mulheres contemporâneas? ${ }^{8}$ (FRASER, 2013, pp.2021).
\end{abstract}

O que a teoria crítica faz - que a teoria tradicional, por exemplo, elimina ou esconde é trazer para a superfície todos os elementos que são problemáticos e contraditórios na nossa condição presente, obrigando a teoria a refletir sobre essas contradições e ir à sua raiz para, através de um reconhecimento ou consciência, poder compreender, explicar e transformar. Não é possível explicar o real ignorando as partes do qual esse real se constitui e perpetua; por outras palavras, não é possível olhar para a história da filosofia e escolher ignorar a ausência das mulheres. A própria história da filosofia, e os vários textos de diferentes autores denunciam a dinâmica e especificidade do seu tempo: é importante não só aquilo que aparece, que é visível, que é dito, mas também - e sobretudo - aquilo que é invisível e não dito. Se estudamos no idealismo alemão Kant, Herder, Hegel, Fichte, entre tantos outros, porque só estudamos obras de homens? As mulheres não existiram? Não tiveram nada a dizer? Como compreender a sua ausência?

Poderia aqui tentar oferecer um olhar fenomenológico sobre a questão do gênero, usando a primeira pessoa como ponto de partida para uma análise; porém, na linha de Haslanger e da própria teoria crítica, prefiro olhar para o problema ou realidade do gênero a 
partir de uma análise de como as relações e estruturas sociais estão sistematizadas. Com efeito, compreender o fato de uma desproporção entre homens e mulheres nos departamentos de filosofia remete a considerações mais amplas, acerca do modo como o horizonte físico e simbólico se constitui e se perpetua e obriga a confrontar dois tipos analiticamente distintos de preocupações mas que estão entrelaçados: por um lado, a preocupação de compreender e mapear a forma como as relações humanas se estabelecem e se justificam ao longo do espaçotempo traduzindo-se em 'normas'; por outro, avaliar a legitimidade dessas normas. Assim, estas preocupações desdobram-se numa dupla tarefa: a tarefa de descrição da prática social, i.e., dos elementos que constituem a matéria a ser avaliada; e a tarefa avaliativa e/ou prescritiva, i.e., de explicitação (e justificação) de conceitos normativos, a partir dos quais se faz uma avaliação das práticas, por exemplo, quando dizemos que uma prática é 'útil', 'justa', 'boa', 'razoável', etc. Como Haslanger bem nota, os filósofos tendem a negligenciar o primeiro nível de análise, enquanto que os outros cientistas sociais tendem a ser mais insensíveis ao segundo, porque geralmente se perdem nas distinções necessárias entre domínio normativo e meta-normativo (HASLANGER, 2012, p. 16).

Um dos temas clássicos da teoria crítica encontra-se na problematização da 'razão' e do 'racional'. Neste contexto (mas não limitado a ele) a resistência feminista aos ideais da razão desdobra-se em duas frentes: por um lado, ela recusa o predomínio da Razão, na medida em que a escolha pela razão supõe necessariamente a rejeição de muitas outras coisas ou faculdades, i.e., ao escolher a razão deixamos de fora outros elementos igualmente importantes, se não mais importantes. Esta recusa traduz-se num abraço consciente pelo lado ou perspetiva 'feminina'. Assim chegamos a uma redefinição da razão em que esta tem um lado masculino e outro feminino. Por outro lado, esta tentativa de redefinição de razão não é considerada suficiente por muitos, na medida em que a apreciação do feminino não elimina, por si só nem de forma automática, a lógica de opressão e dominação que está embutida no discurso 'racional'. Isto sugere que aquilo que poderia aparecer inicialmente como movimento de resistência, visando a transformação (e não esqueçamos que a teoria crítica se assenta num discurso de emancipação humana), acaba reforçando o status quo e as relações de poder já estabelecidas e consolidadas. Assim, o real desafio seria 'não de equilibrar o valor da razão com os valores femininos, mas o de desafiar os nossos compromissos com os ideais racionais.' (HASLANGER, 2012, p. 36) ${ }^{9}$

Este desafio é real e tudo menos evidente. O que significa, de fato, questionar os 'nossos compromissos com os ideais racionais'? Pode significar qualquer uma das seguintes opções: a) suspender as nossas crenças, valores, e a especificidade do nosso olhar e 
experiência; b) criticar os valores dominantes da nossa cultura; c) avaliar de forma plena e autônoma as escolhas que temos entre mãos e escolher, conscientemente, os valores que queremos abraçar. Qual o problema com esta hipótese? Claramente, queremos questionar os nossos compromissos a partir de um plafond ainda 'racional', ou por outras palavras, mesmo fazendo o exercício proposto por Rawls em Uma Teoria da Justiça, e imaginando uma posição original onde desconhecemos tudo acerca de nós mesmos, de forma a identificar os princípios de justiça que irão regular a construção das instituições, esse exercício é um exercício de razão e enquanto exercício tem uma história - a razão tem uma história, não é uma 'faculdade' vazia. Que opção teríamos? Talvez em vez de suspendermos as nossas crenças e valores, analisarmos de que forma essas crenças e valores fazem 'parte' de nós enquanto indivíduos e corpo coletivo; de que forma a sua adopção foi refletida, automática ou imposta; de que forma a nossa vida pautada por valores e normas pré-estabelecidos suporta ou contesta esses mesmos valores e normas; como pensamos e sentimos esses valores, i.e., a) como aceitamos a justificação pública dada e b) como testamos a sua legitimidade. ${ }^{10}$

Quer no primeiro, quer no segundo caso, deparamo-nos com o problema do juízo, da avaliação. Esse, a meu ver, é o maior problema, aquele que nos coloca o real desafio. Assumamos que a avaliação é guiada pelo reconhecimento de que o que está errado no mundo é o sofrimento. Como já dizia Horkheimer em 1937, a crítica deve incidir sobre o sofrimento, não só como categoria de análise, mas como realidade humana palpável que permite estabelecer ou usar um critério de avaliação acerca da vida e existência humanas. O sofrimento, visível na discriminação racial, na discriminação de gênero, em vários mecanismos de exclusão social, é, objetivamente, um obstáculo à critica social e à transformação social (RENAULT, 2010, pp. 224-5). Neste sentido, a descrição do sofrimento é já crítica e denúncia do que está errado, do que é falso no mundo (RENAULT, 2010, p. 239). $\mathrm{O}$ confronto com o sofrimento obriga, mesmo que não se queira ou saiba como, a imaginar uma alternativa, um mundo possível.

A imaginação começa com o questionamento do 'dado' e das 'normas'. Haslanger mostra brilhantemente como existe uma norma epistêmica e prática de grande complexidade a norma da 'objetividade assumida' - que serve ao papel do sujeito que objetifica. Lembremonos que, se Descartes delimitou o desafio da filosofia ao problema do conhecimento e à tentativa de responder 'o que posso conhecer?', foi Kant quem radicalizou e revolucionou a tarefa da filosofia, redefinindo o sujeito epistêmico. O sujeito não é essência, mas função; uma função que objetifica, i.e., que literalmente cria objetos de conhecimento. O movimento 
de objetivação está presente não só na busca de conhecimento mas também na forma como os sujeitos se relacionam entre si; mais especificamente, na forma como os homens se relacionam com as mulheres. A razão teórica define-se a partir desta capacidade de objetivação, o que por outras palavras significa que a objetivação se torna o ponto a partir do qual a razão é (re)definida. A teoria crítica denuncia esta limitação e estreitamento da razão, denunciando a irracionalidade a que esta instrumentalização conduz. ${ }^{11}$

Nesta mesma linha, considero que, se a racionalidade é moldada pela questão do gênero, deparamo-nos hoje com a tarefa de repensar e re-projetar a tradição filosófica ocidental, num horizonte que não seja exclusivamente definido pelos ideais da razão e dos sujeitos racionais. O que significa isto?

Em primeiro lugar, que nos abrimos à re-conceptualização da razão e de nós mesmos e este 'nós mesmos' não se refere a subjetividades em abstrato mas a homens e mulheres concretos que estão sempre em relação. Todos sabem que há uma diferença entre sexo e gênero: sexo é anatómico; gênero aponta para uma relação social. Definimos o gênero com base nas relações sociais que estabelecemos com os outros. Ou seja, uma mulher é mulher não por ter x características fisionômicas, mas por ser parte de um sistema de relações sociais onde existem também homens. Como diz Haslanger, "Gênero é uma propriedade extrínseca ou relacional de indivíduos, e as relações em questão são sociais.” (HASLANGER, 2012, p. 41) Mas então, que relações sociais constituem o gênero?

Se eu disser "o bom escravo é aquele que é obediente" ou "o bom senhor ou mestre é aquele que sabe controlar e mandar nos outros", vocês com certeza repudiariam as minhas afirmações. Aprendemos com Rousseau que a liberdade é inalienável. O que isto mostra é que as ideias acerca de como o escravo ou senhor devem ser não justificam a instituição da escravidão, 'porque os ideais ganham a sua força prescritiva apenas num contexto onde eles assumem a correção (ou inevitabilidade) dos papéis sociais de senhor e escravo.' (HASLANGER, 2012, p. 46) Ou seja, um ideal é apropriado apenas na medida em que é justificado desempenhar esse papel social; mas o ideal apenas não justifica o papel. Isto serve apenas para mostrar que o valor que atribuímos à masculinidade ou à feminilidade não podem ser separados do valor que atribuímos ao desempenho desses papéis. Logo, a tarefa é complexa: criticar e denunciar um sistema de dominação (masculina) sem cair num estereótipo ‘feminino' que acaba reforçando o status quo. Isto conduz-nos ao segundo ponto.

$\mathrm{Na}$ tarefa de reconstruir uma virtude humana ideal, percebemos que temos de abandonar qualquer aspiração essencialista. Dito por outras palavras, não tem como definir a 'natureza humana' e assim, definir o que é especificamente 'masculino' versus o que é 
especificamente 'feminino'. Se temos pretensões essencialistas devemos prescindir da crítica, já que, se as normas 'objetivas' refletem apenas o que é, e se o que é, é necessariamente aquilo que deve ser (i.e., pelo fato de não poder mudar por ser 'natural' ou 'intrínseco'), então não é possível justificar o nosso impulso inquisitivo. Os padrões normativos existentes, por si só, reforçariam a nossa adesão a essas normas. Porém, sabemos, porque sentimos também, que os padrões impostos ainda não são o que devem ser. É a intuição de que há algo de errado que nos indica que tem de ser mudado, e a mudança só ocorre se partirmos desse juízo de que $o$ que é, é falso.

ara concluir queria deixar algumas reflexões, que apenas procuram percorrer um pouco mais desta breve digressão sobre as mulheres na filosofia. Tentei, nestas poucas páginas, mostrar algumas camadas - e linhas inquisitivas - presentes na relação entre gênero e filosofia; tentei mostrar, a partir de uma postura crítica que tem também ela uma história, que devemos desconfiar de todas as posturas ou posições filosóficas que reivindicam a verdade para si, ou, no caso mais específico, a própria emancipação das causas (neste caso, a emancipação das 'mulheres' face a uma lógica de dominação e submissão). O que mais me interessa, e por isso aquilo que mais valorizo na teoria crítica é, como a passagem citada de Fraser retomando Marx, a coragem de se comprometer abertamente com algo, com um discurso, com um lado, com uma 'parte'. E esta coragem e compromisso mostram, em última análise, que a filosofia nunca pode ser neutra, pois mesmo as correntes que reivindicam neutralidade apenas escondem a escolha politica que fazem, consciente ou inconscientemente.

Assim, como conclusão, quero deixar uma reflexão sobre esta relação entre política mulher(es) - vida, a partir de Arendt e Fraser.

Hannah Arendt disse uma vez que 'Parece às vezes que certas pessoas estão tão expostas nas suas vidas (e apenas as suas vidas, não como pessoas!), que elas se tornam, por assim dizer, pontos de ligação e objetivações concretas de vida.' (em KRISTEVA, 2001, p. 3). Arendt coloca a vida no centro da sua vida, como ela põe o pensamento em ação, como vida, como o pensamento é vida. E a vida é uma categoria fascinante, porque ela não é só categoria, ela é vida. Arendt capta com excelência o valor do único, de cada nascimento que inaugura o que ela chama por 'milagre da vida'. Como ela diz:

O novo sempre acontece à revelia esmagadora das leis estatísticas e de sua probabilidade que, para fins práticos e cotidianos, equivale à certeza: assim, o novo sempre surge sob o disfarce do milagre. O fado de que o homem é capaz de agir significa que se pode esperar dele o inesperado, que ele é capaz de realizar o infinitamente improvável. E isto, por sua vez, só é possível porque cada homem é 
singular, de sorte que, a cada nascimento, vem ao mundo algo singularmente novo. Desse alguém que é singular pode dizer-se, com certeza, que antes dele não havia ninguém. Se a ação, como início, corresponde ao fato do nascimento, se é a efetivação da condição humana da natalidade, o discurso corresponde ao fato da distinção e é a efetivação da condição humana da pluralidade, isto é, do viver como ser distinto e singular entre iguais. (ARENDT, 2010, pp.190-1)

$\mathrm{E}$

\begin{abstract}
O milagre que salva o mundo, a esfera dos negócios humanos, de sua ruina normal e 'natural' é, em última análise, o fato do nascimento, no qual a faculdade de agir se radica ontologicamente. Em outras palavras, é o nascimento de novos seres humanos e o novo começo, a ação de que são capazes em virtude de terem nascido. Só o pleno exercício dessa capacidade pode conferir aos negócios humanos fé e esperança, as duas características essenciais da existência humana que a antiguidade ignorou por completo, desconsiderando a fé como virtude muito incomum e pouco importante, e considerando a esperança como um dos males da ilusão contidos na caixa de Pandora. Esta fé e esta esperança no mundo talvez nunca tenham sido expressas de modo tão sucinto e glorioso como nas breves palavras com as quais os Evangelhos anunciaram a 'boa nova': 'Nasceu uma criança entre nós.' (ARENDT, 2010, p. 259).
\end{abstract}

O que Arendt nos oferece é a perspectiva que rompe com a narrativa dominante da construção de uma 'mente', de uma razão, que culminou nas categorias universais e ideologias diversas que destroem aquilo que querem preservar; Arendt cria um espaço no qual podemos construir o nosso próprio ponto de partida para a reflexão acerca das 'mulheres na filosofia', ao dizer que é a ação, no seu carácter revelador e na sua capacidade de produzir estórias e tornar-se histórico, que marca e confere sentido à própria existência humana. Dito por outras palavras, a vida define-se pela atividade incessante de inquirir acerca do sentido e

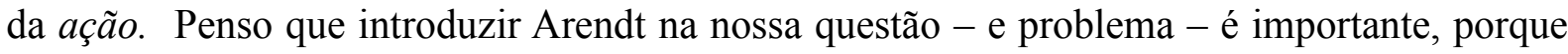
nos permite ganhar uma dimensão mais fenomenológica acerca da própria experiência de vida, de uma vida que nasce sempre de uma mulher. Arendt convida-nos a criar novos 'nós' e a criação de um 'nós' é sempre um ato político - e com isso desconstruir, pela prática, as narrativas dominantes e atribuir novos sentidos à experiência e vida, individual e coletiva. A questão não é 'o que somos nós?' ou 'o que são as mulheres?', ou 'o que fazem as mulheres na Filosofia?'; a questão torna-se ‘quem somos nós?’ A enfâse no quem permite abrir para a construção de nós mesmas.

Esta construção deve ser feita a partir do lugar onde nos situamos. Isto pode parecer fácil, mas não o é necessariamente. Por que? Sobretudo porque a reconstrução de nós mesmas passa por lentes políticas, conceptuais, ideológicas, que aceitamos e que, de alguma forma, são parte constitutiva de nós. Penso, em particular, na lente política teórico-prática do compromisso que temos com ideais liberais e democráticos, com um discurso que se alicerça na defesa incansável dos direitos. Porém, este ponto de partida teórico, que nós queremos 
acreditar que é o nosso ponto de partida prático, na verdade vem sendo transformado de forma sistemática e constante nos últimos trinta anos, com as ondas do neoliberalismo. Não é possível abraçar simultaneamente a lógica liberal e a lógica neoliberal. Somos sujeitos de um mundo neoliberal, no qual a luta por direitos tenta salvar um discurso que, em última análise, talvez não seja mais o nosso. O que quero dizer com isto? Talvez sugerir que é preciso adoptar outro ângulo a partir do qual se faça a construção de nós mesmas e de uma agenda feminista hoje - e essa agenda feminista é distinta da agenda feminista da primeira e segunda vaga de pós guerra do século passado, porque o paradigma simplesmente mudou. Para Fraser, por exemplo, o feminismo surge, num primeiro momento, nos anos 1950, num contexto de capitalismo estabelecido organizado em torno do Estado, i.e., onde o Estado ainda tinha certo controle sobre os mercados. Este paradigma refletia uma cultura política que postulava um cidadão ideal 'masculino' capaz de colmatar as necessidades da sua família. Porém, já na década de 1960 e 1970 deu-se uma virada no discurso, sobretudo pelo desvelamento de várias injustiças que haviam permanecido nas sombras. A luta dessas décadas não se definia tanto pelo gênero, mas também em termos de classe, raça, sexualidade e nacionalidade. Como Fraser diz ' $[\ldots]$ as feministas da segunda-onda estenderam a busca de justiça para considerar questões anteriormente vistas como privadas, tal como sexualidade, casa, reprodução e violência contra as mulheres. Ao fazê-lo elas expandiram o conceito de injustiça para que este abarcasse não só as desigualdades econômicas, mas também as hierarquias de estatuto e assimetrias de poder político.' (FRASER, 2009, p.103) Neste movimento veio à tona a qualidade sistêmica da subordinação das mulheres, enraizada nas estruturas sociais, como falávamos anteriormente. Isto teve os seus desdobramentos (por exemplo, na retomada da Esquerda), e até recentemente parecia que aquilo que começara como movimento contracultural ou de resistência, se tornara referência dominante social. Isto, porém, não foi uma mera coincidência, e vem exatamente ao encontro do que comecei por dizer acerca do neoliberalismo. O que o neoliberalismo fez foi atribuir novos significados às lutas feministas. Em que sentido? Tornando mais difícil conceber o que seria afinal uma agenda emancipatória num contexto de capitalismo organizado em torno do Estado. A mudança do discurso da redistribuição para o reconhecimento cumpriu a tarefa desejada pelo neoliberalismo, a saber, reprimir a memória da luta pela igualdade em nome do reconhecimento da especificidade do grupo ou da cultura; ou seja, ao trocar um paradigma por outro, as feministas ficaram cegas para aquilo que realmente mais importava, a saber, a crítica da economia política, ou simplesmente, a crítica social. Progressivamente, os discursos ganham uma autonomia e 
separam-se das circunstâncias econômicas que no início the eram imanentes. (FRASER, 2009, p.109) Como resgatar condições para um discurso emancipatório feminista, se o 'dano' neoliberal já foi feito, se a nossa natureza humana já foi transformada? Não é possível 'voltar atrás', apenas partir do que temos - e isto remete às condições de constituição da própria subjetividade, fragmentada, via tecnologias, etc. - para pensar e imaginar novas formas de luta por justiça social onde redistribuição e reconhecimento são indissociáveis de uma crítica social mais profunda a todas as esferas das nossas vidas, a começar pelo mito tão querido da democracia, como o outro lado (ou condição) da justiça. Assim, começaria por abraçar uma definição que me parece ser mais justa, do feminismo hoje. Feminismo é Humanismo. Feminismo é a ação política conduzida por mulheres que buscam, pela sua ação, transformar a condição da qual partem. Por isso, feminismo deve passar necessariamente pela critica social, pois visa a (re)construção do mundo de acordo com um ideal de emancipação, onde liberdade e igualdade se encontram. 


\section{Notas:}

${ }^{1}$ Professora Adjunta do curso de Filosofia CCHS, Universidade Federal de Mato Grosso do Sul, Campo Grande, MS, Brasil. e-mail: nunesdacosta77@gmail.com

${ }^{2}$ Ver Segundo Discurso. Agradeço aos meus alunos por terem captado este sentido do texto, que nos obriga a questionar a origem da legitimação não só da autoridade política mas das relações sociais primordiais.

${ }^{3}$ http://www.theguardian.com/commentisfree/2015/jul/25/philosphy-women-warnock-baggini-debate. Acesso a 18 de Março de 2016.

4 http://opinionator.blogs.nytimes.com/2013/09/02/women-in-philosophy-do-the-math/?_r=0 Acesso a 18 de Março de 2016.

${ }^{5}$ Acessamos durante o mês de Março de 2016 aos sites institucionais dos cursos de Filosofia.

${ }^{6}$ Ver Women in Philosophy in the UK - Report by the British Philosophical Association and the Society for Women in Philosophy UK, Setembro de 2011. Disponível em: http://www.swipuk.org/notices/2011-0908/Women\%20in\%20Philosophy\%20in\%20the\%20UK\%20(BPA-SWIPUK\%20Report).pdf Acesso a 18 de Março de 2016. O estudo começa exatamente por questionar o porquê da disparidade tão grande entre homens e mulheres nos departamentos de filosofia, quando comparados com outras disciplinas de artes e humanidades. Foram realizados questionários a chefes de departamentos, apurando a percentagem de mulheres nos seguintes segmentos: professor titular, leitor, professor associado, professor assistente, professor temporário, doutorando, mestrando e graduando.

${ }^{7}$ Idem. Acesso a 18 de Março de 2016. Neste mesmo texto encontra-se a referência ao estereótipo 'masculino' associado à matemática.

${ }^{8}$ No original diz: "To my mind, no one has yet improved on Marx's 1843 definition of Critical Theory as "the self-clarification of the struggles and wishes of the age." What is so appealing about this definition is its straightforwardly political character. It makes no claim to any special epistemological status but, rather, supposes that with respect to justification, there is no philosophically interesting difference between a critical theory of society and an uncritical one. But there is, according to this definition, an important political difference. A critical social theory frames its research program and its conceptual framework with an eye to the aims at activities of those oppositional social movements with which it has a partisan - though not uncritical identification. The questions it asks and the models it designs are informed by that identification and interest. So, for example, if struggles contesting the subordination of women figured among the most significant of a given age, then a critical social theory of society for that time would aim, among other things, to shed light on the character and bases of such subordination. It would employ categories and explanatory models that reveal rather than occlude relations of male dominance and female subordination. And it would demystify as ideological rival approaches that obfuscate or rationalize those relations. In this situation, then, one of the standards for assessing a critical theory, once it had been subjected to all the usual tests of empirical adequacy, would be: How well does it theorize the situation and prospects of the feminist movement? To what extend does it serve the selfclarification of the struggles and wishes of contemporary women?" (FRASER, 2013, pp.20-21)

${ }^{9}$ Parece que estamos diante de um paradoxo: na medida em que as mulheres ficam responsáveis por reavaliar o feminino, estaríamos sem querer a reforçar estereótipos tradicionais. "Não deveríamos desconfiar de ideais de feminilidade que foram definidos no contexto da dominação masculina?' (HASLANGER, 2012, p.36) Ver por exemplo os argumentos de Genevieve Lloyd, The Man of Reason: "Male" and "Female" in Western Philosophy (Minneapolis, University of Minnesota Press, 1984), Jane Flex, Nancy Hartsock, entre outros. 
${ }^{10}$ A crítica que Haslanger faz e que eu retomo prende-se com o conceito especificamente moderno de "razão" (e/ou "racionalidade") em que esta afirma a sua superioridade face a outras dimensões igualmente importantes, tais como emoção, intuição, imaginação, etc.

${ }^{11}$ A associação entre irracionalidade e instrumentalização deve ser aqui entendida no sentido da Dialética do E1sclarecimento de Adorno e Horkheimer.

\section{Referências Bibliográficas:}

ARENDT, Hannah, A condição Humana, tradução de Roberto Raposo, Forense Universitária, RJ, 2007.

BROOKE, A.Ackerly, Political Theory and Feminist Social Criticism, Cambridge University Press, 2000.

FRASER, Nancy, "Feminism, Capitalism and the Cunning of History" in New Left Review n.56, Mar/Apr 2009, pp. $97-117$.

HASLANGER, S., Resisting Reality - Social Construction and Social Critique, Oxford University Press, 2012.

HASLANGER, S., "Changing the Ideology and the Culture of Philosophy: Not By Reason (Alone)", em Hypathia, n.23:2, 2008, pp.210-223.

KRISTEVA, Julia, Hannah Arendt - Life as a narrative, University of Toronto Press, 2001.

ROUSSEAU, J.J., Discurso sobre a origem e os fundamento da desigualdade entre os homens, tradução de Paulo Neves, L\&PM Pocket, 2008. 